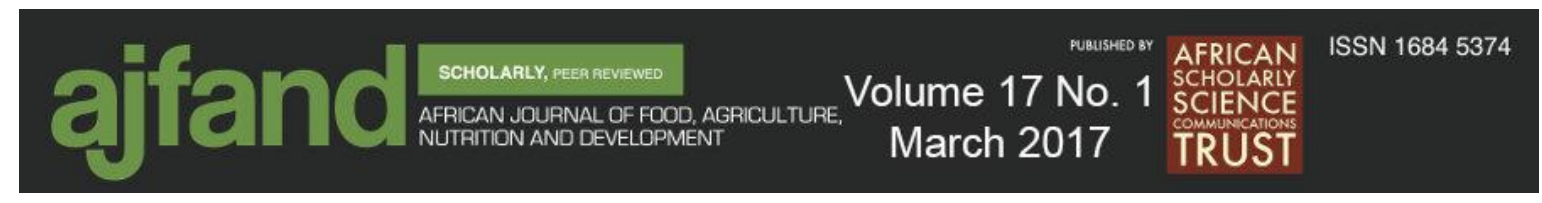

Afr. J. Food Agric. Nutr. Dev. 2017; 17(1): 11497-11517

DOI: 10.18697/ajfand.77.12155

\title{
NUTRITIONAL STATUS AND FOOD CONSUMPTION PATTERNS OF PRIMARY SCHOOL CHILDREN IN ORANGE FARM
}

Nyathela $T^{1^{*}}$ and $W$ Oldewage-Theron ${ }^{2}$

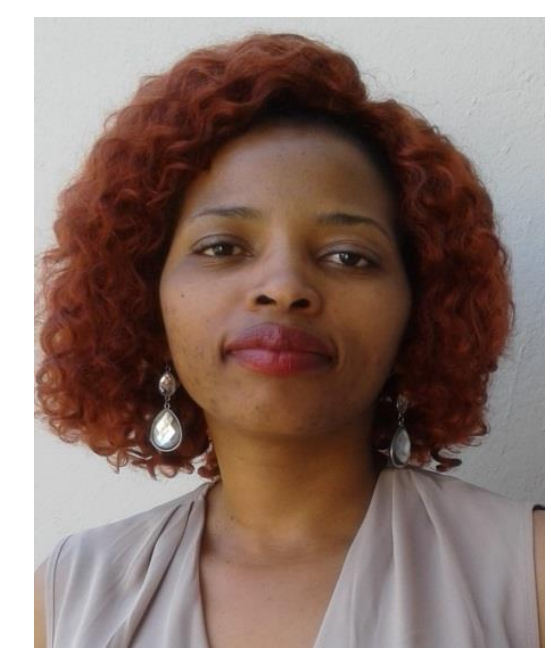

Tshinakaho Nyathela

*Corresponding author email: tnyathel@yahoo.com

${ }^{1}$ Cape Town Hotel School, Faculty of Business and Management Sciences, Cape Peninsula University of Technology, Western Cape, SA

${ }^{2}$ Department of Nutritional Sciences, College of Human Sciences. Texas Tech University, Texas, USA 


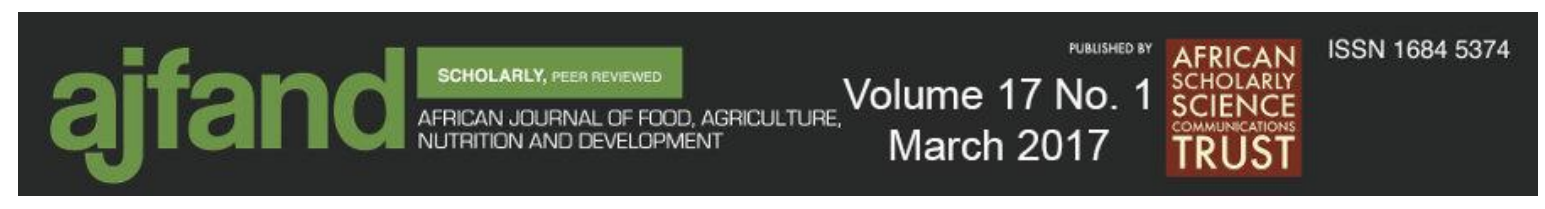

\section{ABSTRACT}

South Africa is regarded as food secure; however, food insecurity and malnutrition are still affecting school-aged children residing mostly in rural areas. This paper reports the nutritional status and consumption patterns of school children from two purposively selected schools located in Orange Farm informal settlement. Data collection methods included socio-demographic background, dietary intakes, anthropometric measurements as well as haematology and biochemical measurements. A socio-demographic questionnaire was used to assess the socio-economic background of the households and a health questionnaire to determine the health background of the caregivers, while a Quantitative Food Frequency Questionnaire (QFFQ) and 24-hour recall were used to determine dietary intake patterns. Anthropometric measurements were obtained in order to find out the prevalence of nutritional status (underweight, wasting and stunting). Haematology and biochemical data collected were used to determine the intake of nutrients and blood levels. Socio-demographic and health questionnaires were captured and analysed using the Statistical Package for Social Sciences (SPSS). Dietary intake, QFFQ and 24-hour food recall were analysed on the South African Medical Research Council FoodFinder ${ }^{\circledR}$ software program. Anthropometric measurements were captured and calculated using Anthro plus then analysed according to the World Health Organisation growth standards while biochemical measurements were analysed using biochemical analyses instrument and transferred to SPSS. The sociodemographic results indicated that household food insecurity contributed to the poor dietary intake of the children as the majority $(71.0 \%)$ of the caregivers were unemployed and further confirmed by household income of less than R1000 (75.0\%) for five to ten household members (44.4\%). Non-communicable diseases were not reported; instead, most of the caregivers had skin problems $(22.2 \%)$ and also suffered from headaches $(20.0 \%)$ as well as body skeletal affections. Mainly carbohydrate-based food was consumed with limited vegetable and fruit intakes. Low energy intakes were reported with sufficient intakes of most of the micronutrients. Anthropometric results indicated that $5.0 \%$ of the children were underweight, only $2.3 \%$ of the children were wasted and $33.3 \%$ were stunted. Haematological and biochemical data indicated that all the variables were within the normal ranges and thus did not indicate any nutrients or blood level deficiency. Through the findings of this study and other similar studies conducted in South African communities, it is evident that poor nutrition and dietary intakes are still prevalent in primary school children. This increases awareness and the immediate need for nutritional status and food insecurity to be addressed.

Key words: Nutritional status, consumption patterns, primary school children, Orange Farm 


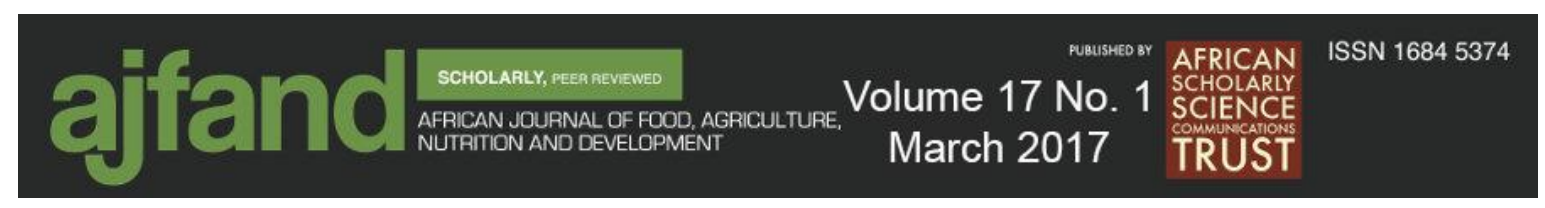

\section{INTRODUCTION}

Fifteen percent (1.02 billion) of the global population is undernourished and the majority are residing in developing countries; this may be caused by agricultural negligence, poor governance and also the global economic crises [1]. Worldwide malnutrition is one of the major causes of ill health, which is responsible for approximately $45 \%$ of deaths in children [2]. Malnourished children are at risk of life threatening diseases such as malaria, pneumonia, diarrhoeal infections, low birth weight and asphyxia [3, 4]. Early childhood severe clinical malnutrition, moderate and severe stunting, underweight and iron-deficiency anaemia are associated with poor cognitive development, behaviour and academic attainment in later childhood. Poor nutrition and hunger are inevitably associated with many other socioeconomic disadvantages, which affect children's performance at school [5].

Malnutrition can be addressed through simple, affordable interventions. When addressing micronutrient malnutrition, a combination of interventions should be used, involving the promotion of breast-feeding, modification of diet, increasing micronutrient bioavailability and consumption as well as increasing food availability, food fortification, supplementation and food diversification, nutrition education and school feeding programmes [6]. In order for the above-mentioned to manifest, a better understanding of nutritional status and food consumption patterns is essential. Additionally, background knowledge on sociodemographic and health information is just as crucial for a holistic overview as the environmental systems such as nature, culture, educational, religious, social and economic status because of their influence on availability, accessibility and utilisation of food [6]. Feeding practices of the children may be affected by the caregiver's poor health status, culture, behavior and also poor socio-economic background [7].

The National School Nutrition Programme (NSNP) in South Africa was introduced in 2003 as one of the strategies to address malnutrition for school-going children [8]. However, malnutrition and poor food consumption are still reported to be prevalent [9]. One of the causes for this may be that there was no research conducted to have an overview of the nutritional and food consumption patterns of the school children in specific areas. This might be one of the determinant factors of high malnutrition risk rates in South Africa [10]. Poor nutrition has a severe impact on the performance of school children $[7,11]$.

To substantiate the above-mentioned, national nutrition surveys were conducted and reported in South Africa. However, there is minimal information reported on people who live in the disadvantaged informal settlements and nothing has been reported specifically on Orange Farm [10]. Thus, this article will indicate a sectional overview on the situational analyses of Orange Farm and more specifically report on the prevalence of malnutrition (wasting, stunting and underweight) and food consumption patterns of children attending independent (Non-Government) Primary Schools in the Orange Farm informal settlement. These findings are aimed at raising awareness, inform and also serve as a reference for Health and Education Ministries, Non-Government Organisations (NGOs), funders and 


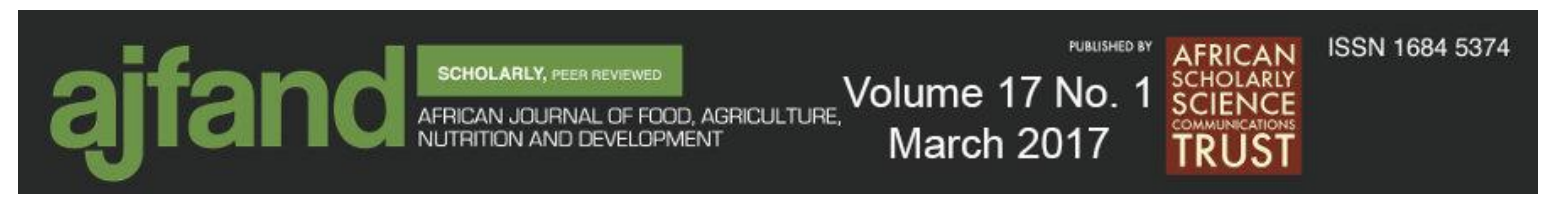

researchers. This will assist them to make informed decisions when introducing and implementing relevant interventions in Orange Farm and other areas with similar sociocultural backgrounds.

\section{METHODOLOGY}

\section{Study design and sample size}

This was a cross-sectional survey conducted in two purposively selected primary schools located in Orange Farm. The sampling frame consisted of children aged between 6 and 13 attending these two schools. The parents and the caregivers gave written consent for the children to participate in the study and the children acquiesced to participate. Fifty $(n=50)$ children participated in the study. Sample size formulas are used to determine representative population for the research to be conducted in order to obtain results that reflect the population targeted. A sample size calculator was used to determine the number $(n=50)$ of children that participated in the study [12].

\section{Research background}

The study was conducted in two independent primary schools located on the south of Orange Farm. Orange Farm is regarded as one of the largest informal settlements in South Africa, located in Region $\mathrm{G}$ on the southern edge $(45 \mathrm{~km})$ of Johannesburg city. The migrants from various Gauteng Province townships occupy this area. Social and economic development opportunities are very limited and as a result, high levels of poverty and unemployment persist [13].

\section{Ethical consideration}

The protocol for this study was submitted in accordance with the South African Medical Research Council guidelines. The University of Witwatersrand Medical School's Medical Ethics Committees for research on human beings approved the study (R14/49). Written consent forms explaining the purpose of the study were read and signed voluntarily by parents or guardians of children. A number was allocated to each consented participant to ensure confidentiality of the information collected and the participant's identity.

\section{Data collection}

In order to encourage undergraduate scholars to participate in research, field workers were students recruited from a tertiary institution and trained to complete a socio-demographic, health, quantified food frequency questionnaire (QFFQ) and 24-hour recall questionnaire and also to take anthropometric measurements. A qualified haematologist assisted by trained biochemistry students from the institution collected haematological and biochemical data. For validity and reliability purposes, fieldworkers who spoke Tshivenda, Xitsonga, Isizulu and Sesotho were involved in data collection because they were able to communicate with the school children and the caregivers in their respective local languages. To ensure accurate data collection, refresher courses were conducted throughout the duration (one week) of data collection.

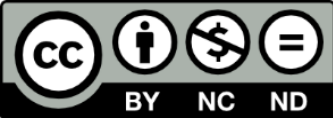




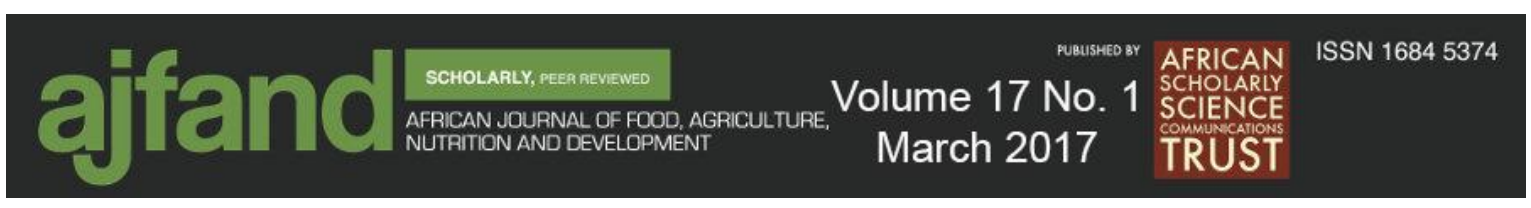

The parents completed all the socio-demographic and health questionnaires with the assistance of the trained fieldworkers. The research team completed quantified food frequency questionnaires (QFFQ) and 24-hour recall questionnaires, with the assistance of the parents as some of the children between the age of six and seven were too young to respond to the questions and also recall the dietary information needed. Data were collected on different days to avoid interruption of scheduled school activities. As a result, out of 50 children that were present during data collection eight (8) were absent on the day that anthropometric data was collected. Thus, anthropometric sample size was forty two (42).

\section{Measuring instruments}

Three techniques were used to collect data. The first was questionnaires; four questionnaires were administered for each of the participants, namely, the socio-demographic questionnaire, the health and medical questionnaire, the QFFQ and 24-hour recall questionnaire. The second was anthropometric measurements (height and weight) and the third was haematological and biochemical measurements.

\section{Socio-demographic and health data}

The socio-demographic questionnaire was developed and validated by the research group of the tertiary institution. The questionnaire included questions on the role of the family, age, accommodation, number of people who are living at home, age of dwelling, type of house, description of the dwelling, home language, the number of residents and rooms in the household, employment status, educational level, the residence setting, the person responsible for preparing meals in the household and the number of meals per day. The validated health questionnaire of Gauteng Provincial Administration (GPA) was used to analyse health background of the caregivers. It includes questions on gender, health status, level of physical activities, frequency of smoking, frequency of drinking alcohol, health facility used, method of travelling to the health facility, number of pregnancies, number of children and description of the child's behaviour.

\section{Dietary intake data}

The validated QFFQ that was used in the Transition and Health during Urbanisation in South Africa (THUSA) study [14] was adapted and used in this study to examine usual dietary intake. The questionnaire consisted of two components, namely a list of the foods and a set of frequency-of-use response categories. An extensive list of defined foods was included with the aim of estimating usual food intake. The 24-hour recall questionnaire is a retrospective approach and served as a reference measure for the QFFQ. It included information about the foods and portion sizes consumed the day before the 24-hour recall was administered. Food models, household measures such as cups and tablespoons were used to estimate portion sizes of the food consumed. 


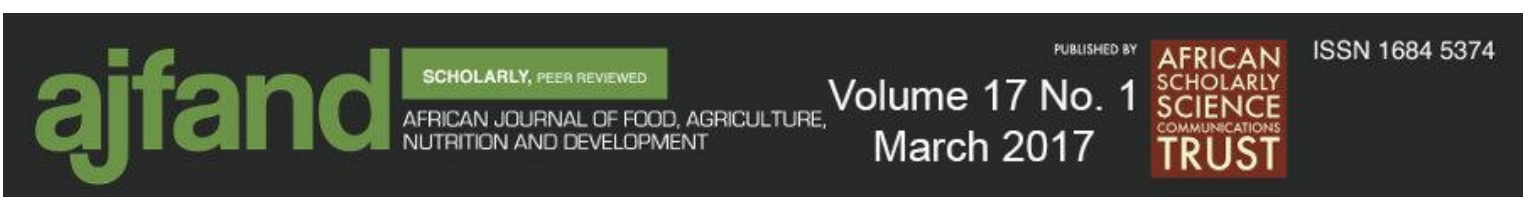

\section{Anthropometric data}

Anthropometric measurements were taken to determine the nutritional status of the school children. These were weight and height. All subjects were weighed in light clothes without shoes on a portable digital electronic calibrated bathroom scale. To ensure accuracy of the measurements, two measurements for weight were taken and they should not have varied with more than $0.1 \mathrm{~kg}$ and the average measurement was used. Height was measured using an upright stadiometer. Two measurements for height were also taken with no more than 0.1 $\mathrm{cm}$ variance and the average was used.

\section{Haematological and biochemical data}

A qualified haematologist collected and analysed the data. Single use vacutainers were used to collect blood samples from each consented subject for haematology and biochemical analysis. The blood was drawn from the vena cephalica of the seated subjects after 8-10 hours fast. Two sets of blood samples were collected from each consented subject. The first set was $5.0 \mathrm{ml}$ of blood in a vacutainer containing the anticoagulant Ethylenediaminetetraacetic acid (EDTA); the whole blood obtained was used to determine haematocrit (Hct), mean cell volume (MCV), red blood cell count (RBC), haemoglobin (Hb) level and white blood cell count (WBC). In the second set, $10.0 \mathrm{ml}$ of blood was collected in a silicone-coated tube. The blood was allowed to clot and then centrifuged to obtain the serum, which was then used for the analysis of serum ferritin, iron, albumin, total protein and transferrin. Blood samples were separated within 2 hours of blood collection. Aliquots of serum were placed in properly labeled Eppendorf tubes and stored frozen at $-10^{\circ} \mathrm{C}$ until analysis. All analysis was carried out using standard haematology and biochemical procedures $[15,16]$.

\section{Data analyses}

Socio-demographic and health data were captured on an Excel spreadsheet and analysed using the Statistical Package for Social Sciences (SPSS) version 20.0. Data was interpreted using descriptive statistics and presented in the form of frequencies and percentages in order to respond to all of the questions in the questionnaires.

The QFFQ and 24 hour recall were analysed, with the assistance of a dietician, on the South African Medical Research Council FoodFinder® software program based on the South African food composition tables to establish the nutrient intake and top 20 most commonly consumed foods [15]. The data were analysed for the lowest, mean and the highest intakes of all the nutrients and compared to the dietary reference intakes (DRIs), Estimated Average Requirement (EAR) and Adequate Intake (AI) for children aged 9-13 years [17].

Anthro plus was used to analyse anthropometric data. The WHO growth standards (2007) for children aged 5 to 19 years were used for statistical comparison of the anthropometric indicators [18]. Height and weight measurements were classified according to weight-for- 


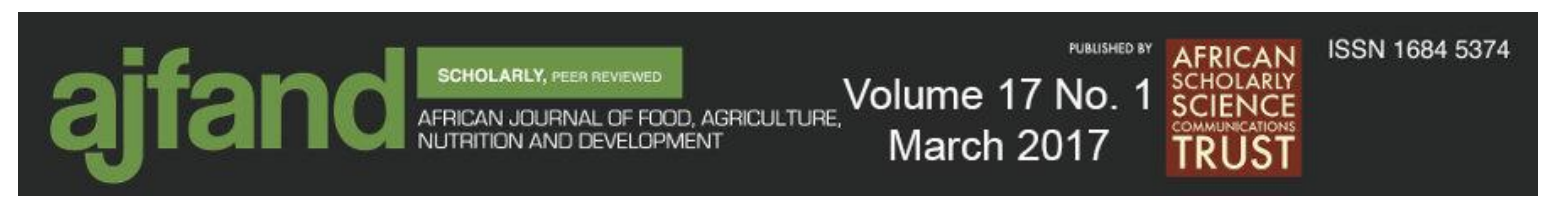

age to determine whether children were underweight $(<-2$ SD) or severely underweight (<-3 SD); height-for-age to determine if the children were stunted $(<-2$ SD) or severely stunted (<-3 SD) and body mass index for age (BMI-for-age) to find out if the children were wasted $(<-2 \mathrm{SD})$ as well as severely wasted $(<-3 \mathrm{SD})$.

Both haematological and biochemical data (Red blood count, haemoglobin, haematocrit, mean cell volume, white blood count, total protein, albumin, iron, ferritin and transferrin) were captured on the SPSS, version 20.0. Descriptive statistics (means, standard deviations) were determined and means were compared with reference ranges.

\section{RESULTS}

\section{Socio-demographic and health background}

For the purpose and relevance of this study, socio-demographic and health status results were also reported [7]. All the participants resided in an urban informal settlement (Orange Farm). The majority of the caregivers/parents $(71.0 \%)$ were unemployed, receiving pensions and children's grants on a monthly basis. As a result, the majority $(75.0 \%)$ of the households received less than $\mathrm{R} 1000$ which led to most of the families $(27.0 \%)$ experiencing money shortage. The mean \pm SD age of the caregivers was $45 \pm 67$ years and of the children $10 \pm 2.6$ years. The majority of the participants purchased food once a month $(80.0 \%)$ at supermarkets (87.0\%). Two meals were consumed in most of the households (37.0\%). Fifty-three percent $(53.0 \%)$ of the households had a family size of one to five people, $44.4 \%$ of households were six to ten people and only $2.3 \%$ had ten and above people dwelling in the household. Most $(35.5 \%)$ of the participants had standard ten (currently known as grade twelve) as their highest qualification.

The health results showed that the caregivers/parents had mainly skin diseases $(22.2 \%)$, headaches (20.0\%), affection of skeleton (13.3\%) as well as eye, nose or teeth problems $(13.3 \%)$. Majority $(87.0 \%)$ of the caregivers/parents never smoked cigarettes and $76.0 \%$ never smoked snuff. Only $7.0 \%$ consumed alcohol occasionally.

\section{Food consumption patterns}

Both Table 1 and Table 2 indicate the top 20 food items consumed as measured by 24-hour recall and QFFQ, respectively. The results in both tables show that most of the top 20 frequently consumed food items were carbohydrate-rich foods. These items included maize meal stiff porridge, white rice, maize meal soft porridge, brown bread/rolls, white bread/rolls, homemade fat cakes, and Mabella (sorghum). No fruits and vegetables were consumed except in the form of fruit and orange juices. The dairy group was represented by full fat, whole milk and milkshake as well as protein group in a form of roasted or boiled chicken and stewed beef.

Table 3 presents the mean dietary intake of nutrients obtained with the QFFQ and the 24hour recall. The QFFQ results indicated that these school children had insufficient intakes

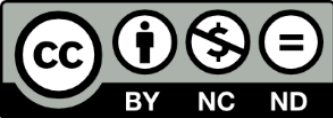




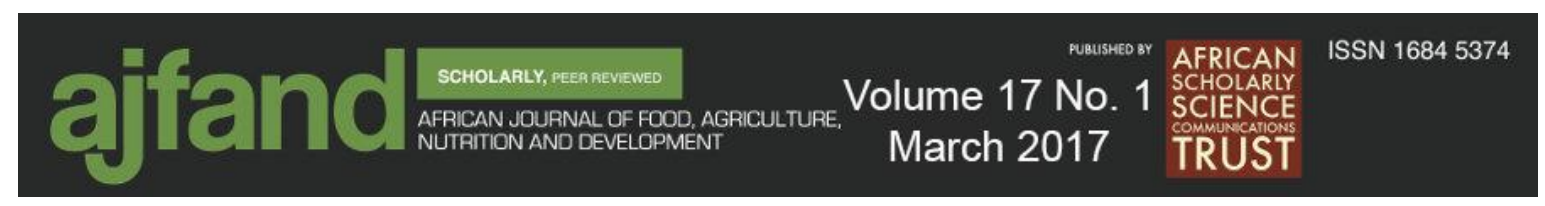

of energy, though the mean intake of the nutrients such as total protein, iron, chromium, vitamin A, riboflavin, niacin, biotin, and vitamin B6, B12, C and D were sufficient when compared to the EAR/AI. However, for most of these nutrients, less than $25 \%$ of the children had adequate intakes when compared with the DRI. A similar trend was observed with the dietary intakes as measured by the 24-hour recall (Table 3). However, for most nutrients, a higher percentage of respondents had adequate nutrient intakes, irrespective of the fact that the percentage was still low for all the nutrients.

\section{Haematology and biochemical results}

Haematological and biochemical data were collected to assess the prevalence of nutrients and blood level deficiency. The results in table 5 indicate that all the variables, namely, red blood count, haemoglobin, haematocrit, mean cell volume, white blood count, total protein, albumin, iron, ferritin and transferrin were within the normal ranges and thus did not indicate any abnormality of deficiency.

\section{Anthropometric measurements}

The results in Table 4 showed that $33.3 \%$ of the children were stunted (<-2 SD) of which $14.3 \%$ were severely stunted $(<-3 \mathrm{SD}) ; 2.3 \%$ of the children were underweight $(<-2 \mathrm{SD})$ of which $2.3 \%$ were severely underweight $<-3$ SD); $5.0 \%$ (<-2 SD) were wasted of which $0.0 \%$ were severely wasted $(<-3 \mathrm{SD})$. On the other hand, $2.3 \%$ were obese $(\geq+3 \mathrm{SD})$ of which $4.7 \%(\geq+2<+3$ SD) were overweight and $30.0 \%$ were at risk of being overweight $(>+1 \mathrm{SD})$.

\section{DISCUSSION}

Statistics South Africa (SSA) reported that school children between the ages of seven and eighteen leave school because of various challenges faced such as lack of money for school fees, family commitment and poor academic performance [19]. Orange Farm has limited social and economic development, which leads to $60 \%$ unemployment and as a result, there is continuous migration from the dwellers going to seek better opportunities elsewhere [20]. These statements emphasize the absenteeism of eight (19.0\%) school children during anthropometric data collection. This is a challenge of the study as there is variation on the total numbers of the anthropometric data as compared to the other variables reported.

\section{Socio-demographic background and health status}

The majority $(71.0 \%)$ of the caregivers were mothers aged between the ages of 45 and 67 years. A similar situation was found in a study conducted by Kirsten and Marais in the rural area of the Western Cape [21]. Orange Farm dwellers relocated from informal settlements in Gauteng which resulted in higher occupancy with the average of 4 people per household [13]. Comparable results were also evident in this study, which indicated that households had family size ranging between one and five people (44.4\%). Higher occupancy level per household was also reported by Schoeman and co-authors in a study conducted in the rural districts of KwaZulu-Natal and Eastern Cape Province where household size from these two areas ranged between five and ten [22]. Although Gauteng Province is regarded as the 


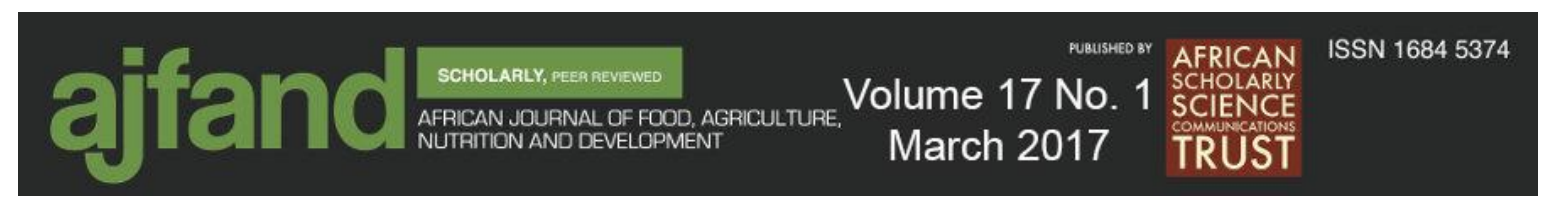

richest province in the country, poverty and household food insecurity is still prevalent in most of the rural communities [23]. This was demonstrated in this study as majorities (71.0\%) of the caregivers were unemployed; the households were relying on pension funds and child grants as a source of income. This was also reported by a study conducted in the Western Cape whereby $66.0 \%$ of the caregivers depended on grants for economic survival [24]. As indicated that pension funds and grants are the main source of income, most of the households (27\%) receive income of less than ZAR1000 (1 USD). This was supported by the study conducted in some of the South African communities which reported that caregivers were unemployed with income of less than ZAR1000 (1 USD) [24]. The results in this study and other supporting studies indicated above report that there is a high prevalence of poverty. This was shown by a high percentage of unemployment and low household income. A national survey also reported similar trends in Gauteng Province; however, it was observed that the percentage of unemployment $(41.9 \%)$, income of less than ZAR1000 (1 USD) (16.1\%), and grants as a source of income (13.0\%) were reported to be less as compared to the percentage found in this study [10]. The majority (62.0\%) of Orange Farm experiences severe food insecurity [19] with $26.6 \%$ experiencing money shortage. Even though the majority (87.0\%) accessed food products from the local food supermarket, $80.0 \%$ of the participants purchased food once a month with $71.0 \%$ consuming two meals per day. Selepe and co-authors also observed similar trends whereby $77.0 \%$ of the households were purchasing food products from the local stores [25].

Medical condition and substance abuse of the care givers may cause feeding problems in infancy and childhood [7]. Considering the above statement, non-communicable diseases (NCD) among adults such as diabetes mellitus, stroke, hypertension, heart disease, asthma and epilepsy were reported as the main causes of death for the past decade [24]. This was also seconded by the national health survey, whereby high blood pressure, heart attack, stroke and high blood sugar were reported in the Gauteng Province with $25.7 \%, 4.4 \%, 5.1 \%$ and $19.4 \%$, respectively [10]. However, in the current study these diseases were not prevalent; instead caregivers reported to be suffering mainly from skin diseases $(22.2 \%)$, headaches (20.0\%), and affection of skeleton (13.0\%), as well as eye, nose or teeth problems $(13.0 \%)$. Some of the diseases reported above such as headache problems, skin diseases and nervous system problems and other problems such as urinary and gynaecological diseases were also reported in the study conducted by Bradshaw and co-authors [26]. The majority of the caregivers did not smoke $(87.0 \%)$ or consume alcohol $(93.0 \%)$. These results have been found to be consistent with national surveys conducted in South Africa [10, 24].

\section{Food consumption patterns}

South African communities consume mainly plant-based staples and low animal foods, vegetables and fruits [27]. This was observed in this study whereby mainly carbohydraterich foods were consumed with little animal protein, vegetables or fruits. Socio economic status affects and determines food availability, in terms of quantity and quality and in relation to the economy status, cultural and food practices of the households [28]. Poor households' economic status might have contributed to the food consumption patterns stated above as 


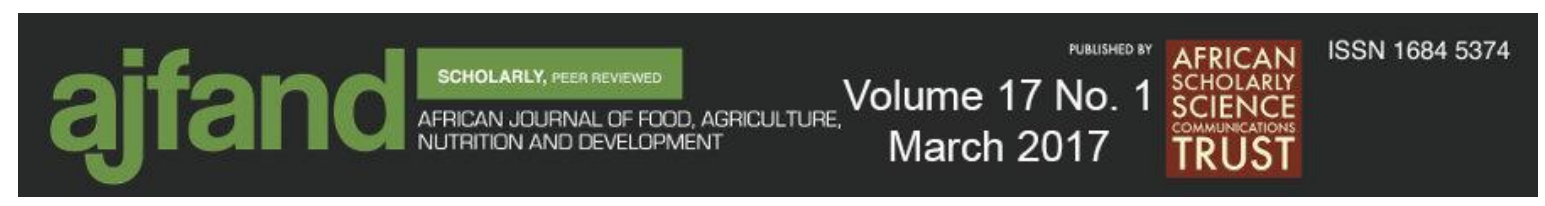

majority of the participants consumed carbohydrate-rich foods (staple food). From the 24hour food recall questionnaire that was used to assess the top 20 items consumed over a period of 24 hours, the results showed that all participants consumed maize meal porridge, tea, white rice, brown bread, and chicken. Nevertheless, total energy intake was insufficient when compared to Estimated Average Requirement (EAR) of school-aged children. Quantitative food frequency questionnaires that assessed consumption patterns over a period of seven days also revealed that the participants had low energy intake compared to EAR. On the contrary, school children had sufficient intake of some of the nutrients such as total protein, iron, chromium, vitamin A, riboflavin, niacin, biotin, and vitamin B6, B12, C and $\mathrm{D}$ when compared to the EAR. Comparable findings were reported in a study conducted in Durban whereby some of the participants had low energy intake and high intake of the micronutrients [27]. Lower energy intake could have resulted from the number of meals consumed (two) and the portion size versus the quantity (120-175g) needed per serving by the age group. One of the major determinants has been the socio-economic status of income less than R1000 per month, which is unable to sustain the number of individuals ranging from three and above (65\%) in the household. Seo Yeon Jang stated that income is needed to fulfill a satisfactory standard of living depending on the household size and composition [28]. This was also evident on the United Kingdom (UK) national diet and nutrition survey of young people aged between four and eighteen years whereby it was reported that children residing in the lower socio-economic households had insufficient energy intakes [29]. On a positive note, staple foods have been fortified with micronutrients (Vitamin A, Thiamin, Riboflavin, Niacin, Folic acid, Pyridoxine, iron and zinc) in South Africa in order to promote adequate micronutrient intake [30]. These may have contributed to the sufficient intake of certain micronutrients such as iron, vitamin A, riboflavin and niacin. Furthermore, there were vendors selling affordable fruits and vegetables on the streets of Orange Farm and some of the households had vegetable gardens and this might have had an impact on the sufficient intake of the majority of the micronutrients as presented in table 3.

\section{Haematology and biochemical status}

Haematology and biochemical findings support the dietary intake results reported using QFFQ and 24-hour recall, which indicated that there was sufficient intake of some of the micronutrients. Nutrients that appeared to be sufficient on both nutrient intake and biochemical results were total protein and iron. Their overall results indicated neither nutrients nor blood level deficiency. This contradicts studies that were conducted in South Africa and some developing countries $[14,29]$. The latest South African results that were reported on children of different age groups indicated that anaemia is still prevalent $(10.7 \%)$ and that haemoglobin and ferritin were within the normal range as well as only $1.9 \%$ had iron deficiency anaemia [10]. Nevertheless, these findings do not give a true reflection as the findings reported are for different age groups and there are no current results reported for the age group similar to the one of this study. 


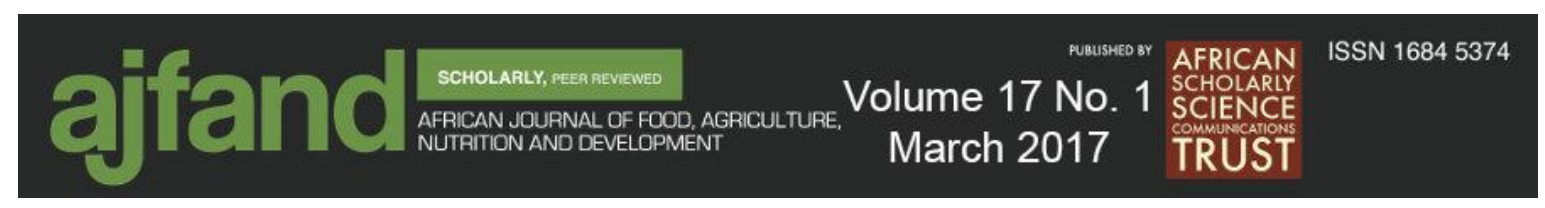

\section{Anthropometric status}

Prevalence of stunting (19.3\%), underweight (25.6\%) and wasting (9.2\%) among children attending school was reported to be high [31]. This study also confirmed the above findings with the prevalence of stunting, underweight and wasting being 33.3\%, $2.3 \%$ and 5.0\%, respectively. Prevalence of stunting and wasting was found to be high in this study as opposed to $9.4 \%$ and $1.9 \%$ reported by the national survey. Further, underweight was reported to be low as compared to $6.6 \%$ reported by the national survey [32]. A challenge of overweight (4.7\%) and obesity $(2.3 \%)$ was evident in this study. These results are similar to previous studies conducted in South Africa where overweight and obesity were reported to be prevalent amongst children aged 1-9 years old [33, 34].

\section{Summary of the main findings}

Malnutrition in children is still a problem in South Africa and other African countries [35]. This is affecting the nutritional status of the children. Because of malnutrition, children fail to grow and develop adequate cognition [36]. Poor food consumption is one of the contributing factors. Rural population is relying more on purchasing food from informal food retailers and fast food outlets selling unhealthy food [37]. Due to poor economic status the majority of the population consumes carbohydrate-based staple food. On the other hand, fortification of staple food and other food products is assisting with the reduction of low micro-nutrient intake [30]. These were observed in this study population whereby caregivers of the school children were unemployed, receiving less than ZAR1000 (1 USD) a month. Even though the majority of the participants consumed mostly carbohydrate-based foods, they also had sufficient intake of macronutrients and micronutrients except for energy when compared to the EAR. The low energy intake was further confirmed by the high percentage of stunting followed by underweight and wasting, with low prevalence of overweight and obesity. Low energy intakes have a negative impact on height genes, metabolism, behaviour and the environment; furthermore, prolonged dietary deficit may result in reduction of physical fitness in school children [38, 39, 40]. Few nutrients and blood levels were analysed because of limited funds. The nutrients assessed confirmed the sufficient intake of total protein and iron. Furthermore, no blood levels deficiency was observed, which means that there was no indication of iron deficiency or anaemia. Most of the results reported deviated from the national health and nutrition findings reported.

\section{CONCLUSION}

Currently the world is facing malnutrition as one of the biggest health problems that leads to child mortality annually especially in poor communities [34]. This study demonstrated that this was a low-income community with poor dietary intakes that may have resulted in the prevalence of malnutrition in the primary school children. Therefore, it is of great importance to conduct baseline analyses before implementing programmes that are aimed at improving the nutritional status of the school children and any other age groups [41]. 


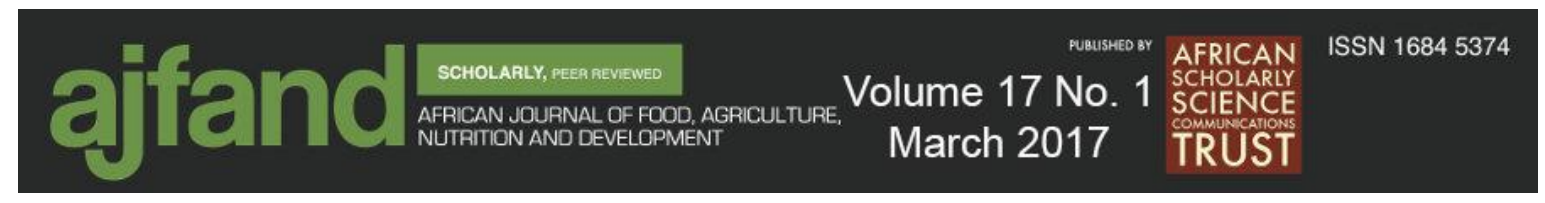

Feeding practices are very important especially during infancy for development, growth and health $[42,43,44]$. Thus, nutrition education programmes should be implemented in primary schools as part of the curriculum so that children are made aware of healthy food choices and also improve nutritional knowledge and practices $[43,45,46]$. The findings of this study are strongly in agreement with the statements mentioned above as it is evident from the results that varying relevant approaches are required depending on the location and the circumstances. There is scanty literature report on the low energy intakes of South African school children, which was evident in this study. Therefore, more research needs to be conducted on prevalence of low energy intake in children and the impact thereof.

\section{ACKNOWLEDGEMENTS}

The authors express gratitude to the National Research Foundation (NRF) for funding the study, field workers' assistance for the support, primary schools, children as well as caregivers who participated in the study. 


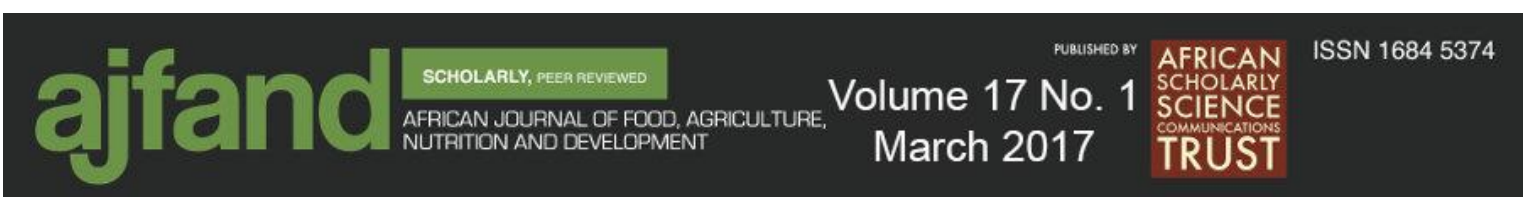

Table 1: Top 20 most commonly consumed food items as measured by 24-hour recall

\begin{tabular}{lllll}
\hline Food items & $\begin{array}{l}\text { Total intake } \\
\text { in grams }\end{array}$ & $\begin{array}{l}\text { Number of } \\
\text { subjects who } \\
\text { consumed the } \\
\text { food items }\end{array}$ & $\begin{array}{l}\text { Mean intake }(\mathrm{g}) \\
\text { in 24 hours }\end{array}$ & SD \\
& & & \\
& &
\end{tabular}

\begin{tabular}{lllll}
\hline Maize meal, cooked, stiff & & & & \\
porridge & 16300 & 50 & 326 & 197 \\
Tea, brewed & 19660 & 50 & 297 & 283 \\
Rice, white, cooked & 14074 & 50 & 195 & 151 \\
Maize meal, cooked soft porridge & 12280 & 45 & 272 & 122 \\
Bread/rolls, brown & 9290 & 50 & 120 & 71 \\
Chicken, meat and skin, boiled & 5437 & 50 & 102 & 50 \\
Bread/rolls, white & 5075 & 47 & 107 & 32 \\
Fruit juice, mixed & 4850 & 19 & 255 & 187 \\
Coffee, brewed/ instant & 3725 & 16 & 232 & 76 \\
Milk, full fat / whole, fresh & 3560 & 31 & 114 & 91 \\
Cold drink, squash, diluted & 2830 & 16 & 176 & 77 \\
Vetkoek homemade & 2360 & 17 & 138 & 68 \\
Chicken stew (tomato and onion) & 2310 & 21 & 110 & 52 \\
Cold drink, carbonated & 2240 & 11 & 203 & 33 \\
Beef, chuck, cooked & 1990 & 14 & 142 & 48 \\
Water & 1890 & 8 & 236 & 74 \\
Orange juice, fresh & 1850 & 9 & 205 & 16 \\
Chicken, meat and skin, roasted & 1720 & 16 & 107 & 48 \\
Milk shake, vanilla & 1590 & 7 & 227 & 25 \\
Mabella (Sorghum) cooked & 1540 & 5 & 308 & 257 \\
\hline
\end{tabular}

SD- standard deviation 


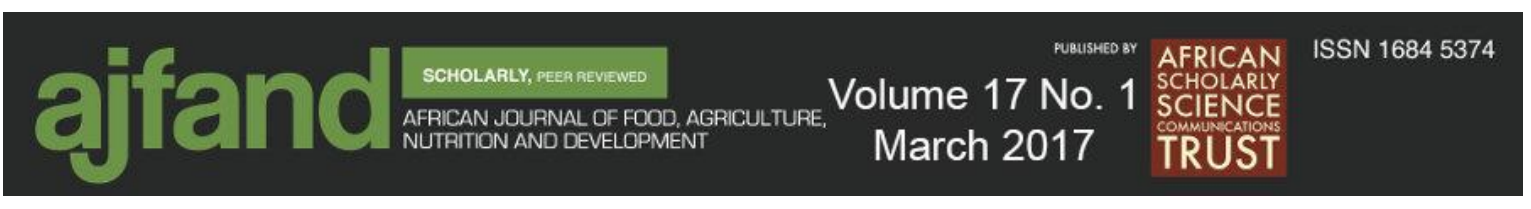

Table 2: Top 20 most commonly consumed food items as measured by QFFQ

\begin{tabular}{|c|c|c|c|c|}
\hline Food items & $\begin{array}{l}\text { Total intake } \\
\text { in grams }\end{array}$ & $\begin{array}{l}\text { Number of } \\
\text { subjects who } \\
\text { consumed the } \\
\text { food items }\end{array}$ & $\begin{array}{l}\text { Mean intake } \\
\text { (g) in } 7 \text { days }\end{array}$ & SD \\
\hline Rice, White, Cooked & 6980 & 22 & 317 & 220 \\
\hline Maize Meal, Cooked, Stiff Porridge & 6880 & 36 & 191 & 106 \\
\hline Tea, Brewed & 3950 & 17 & 232 & 35 \\
\hline Maize Meal, Cooked, Soft Porridge & 3800 & 25 & 152 & 78 \\
\hline Bread/rolls, Brown & 2520 & 29 & 87 & 36 \\
\hline Bread/rolls, White & 2200 & 19 & 116 & 36 \\
\hline Fruit Juice, Average & 1900 & 9 & 211 & 33 \\
\hline Coffee, Brewed/ Instant & 1550 & 6 & 258 & 20 \\
\hline Gravy, Brown, Powder Prepared With & & & & \\
\hline Water & 1386 & 16 & 87 & 91 \\
\hline Milk, Full Fat / Whole, Fresh & 1300 & 13 & 100 & 85 \\
\hline $\begin{array}{l}\text { Chicken, Meat And Skin, Frozen, } \\
\text { Roasted }\end{array}$ & 1240 & 10 & 124 & 67 \\
\hline Stew, Chicken (with Skin), Tomato And & & & & \\
\hline Onion & 845 & 8 & 106 & 43 \\
\hline Chicken, Meat And Skin, Frozen, Boiled & 820 & 5 & 164 & 134 \\
\hline Cold Drink, Squash, Diluted & 650 & 3 & 217 & 29 \\
\hline Stew, Beef, With Cabbage & 520 & 4 & 130 & 70 \\
\hline $\begin{array}{l}\text { Cold Drink, Carbonated, Average (for } \\
\text { example Cola, Cream Soda, Tonic) }\end{array}$ & 440 & 2 & 220 & 170 \\
\hline Salad: Beetroot & 435 & 9 & 48 & 31 \\
\hline $\begin{array}{l}\text { Batter Dipped, Fried Chicken (for } \\
\text { example Kentucky) }\end{array}$ & 420 & 4 & 105 & 30 \\
\hline Sugar, White, Granulated & 398 & 30 & 13 & 5 \\
\hline Cabbage, Sautéed In Sunflower Oil & 364 & 4 & 91 & 73 \\
\hline
\end{tabular}

QFFQ- Quantitative Food Frequency Questionnaire

SD- Standard deviation 


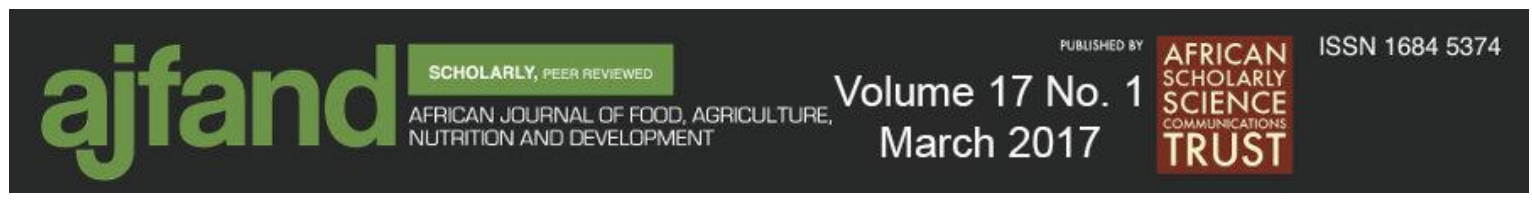

Table 3: Mean dietary intake of energy and nutrients as measured by QFFQ and 24hour recall, their percent of Daily Recommended Intake (DRI) and the EAR for children

\begin{tabular}{|c|c|c|c|c|c|}
\hline Nutrients & $\begin{array}{l}\text { Mean } \\
\text { dietary } \\
\text { intake (n } \\
=50) \\
\text { QFFQ }\end{array}$ & $\begin{array}{l}\% \text { of } \\
\text { respondents } \\
\text { with } \\
\text { adequate } \\
\text { intake (DRI) }\end{array}$ & $\begin{array}{l}\text { Mean } \\
\text { dietary } \\
\text { intake (n } \\
=50) \\
\text { 24-hour } \\
\text { recall }\end{array}$ & $\begin{array}{l}\% \text { of } \\
\text { respondents } \\
\text { with adequate } \\
\text { intake (DRI) }\end{array}$ & $\begin{array}{l}\text { EAR children } \\
\text { aged 9-13 } \\
\text { (Institute of } \\
\text { medicine 1997, } \\
\text { 1998, 200, 2001 } \\
\text { \& 2002) }\end{array}$ \\
\hline Energy kJ & 4573 & 4 & 6214 & 6 & 9572 \\
\hline Total protein $(\mathrm{g})$ & 38 & 20 & 55 & 35 & $34^{*}$ \\
\hline Total fat & 49 & & 47 & & * \\
\hline $\begin{array}{l}\text { Total dietary fibre } \\
\text { (g/day) }\end{array}$ & 8 & 12 & 11 & 1 & $31 *$ \\
\hline $\begin{array}{l}\text { Carbohydrates } \\
\text { (g/day) }\end{array}$ & 137 & 0 & 204 & 32 & $130 *$ \\
\hline Calcium (mg) & 329 & 6 & 204 & 0 & 1300AI \\
\hline Iron (mg) & 6 & 6 & 6 & 21 & 5.9 \\
\hline Magnesium (mg) & 146 & 10 & 200 & 21 & 200 \\
\hline Phosphorus (mg) & 562 & 4 & 690 & 7 & 1055 \\
\hline Zinc (mg) & 5 & 8 & 6 & 19 & 7.0 \\
\hline Chromium ( $\mu \mathrm{g} /$ day) & 30 & 6 & 29 & 17 & $25^{*}$ \\
\hline Selenium ( $\mu \mathrm{g} /$ day) & 30 & 10 & 30 & 14 & 35 \\
\hline Iodine ( $\mu \mathrm{g} /$ day $)$ & 28 & 2 & 21 & 1 & $73 *$ \\
\hline Vit A (RE) ( $\mu \mathrm{g} /$ day $)$ & 647 & 0 & 195 & 3 & 445 \\
\hline Thiamine (mg) & 0.7 & 10 & 0.7 & 25 & $0.7^{*}$ \\
\hline Riboflavin (mg) & 1.4 & 8 & 0.7 & 10 & 0.8 \\
\hline Niacin (mg) & 10 & 2 & 15 & 39 & 9.0 \\
\hline Vitamin B6 (mg) & 0.9 & 6 & 1.0 & 25 & 0.8 \\
\hline Folate (ug/day) & 144 & 4 & 140 & 5 & 250 \\
\hline $\begin{array}{l}\text { Vitamin B } 12 \\
(\mu \mathrm{g} / \text { day })\end{array}$ & 19 & 2 & 1.3 & 14 & 1.5 \\
\hline Pantothenate (mg) & 2 & 6 & 6.0 & 28 & $4.0^{*}$ \\
\hline Biotin ( $\mu \mathrm{g} /$ day $)$ & 27 & 2 & 17 & 12 & $20 *$ \\
\hline Vitamin C (mg) & 77 & 4 & 72 & 11 & 63 \\
\hline Vitamin $D(\mu \mathrm{g} /$ day $)$ & 4 & 24 & 2.0 & 5 & $5 *$ \\
\hline Vitamin E (mg) & 8 & 14 & 6.1 & 8 & 9 \\
\hline
\end{tabular}

$\mathrm{EAR}=$ Estimated average requirement

QFFQ= Quantitative Food Frequency Questionnaire $*=$ Adequate intake 


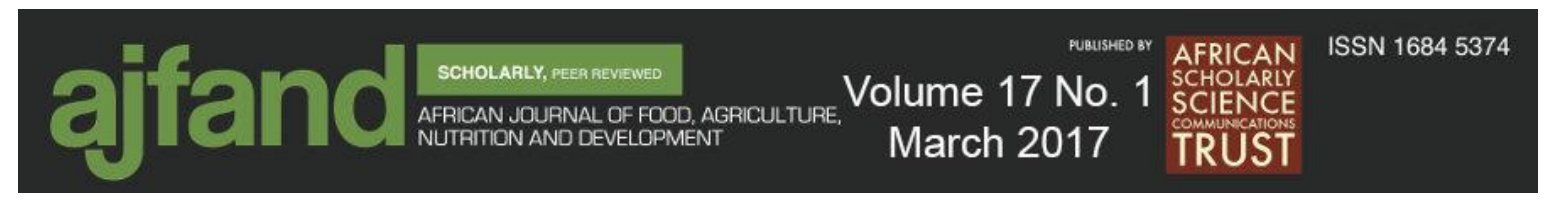

Table 4: Anthropometric results; underweight, wasting and stunting

Cut-off point

Classification

Number (\%)

\begin{tabular}{llr}
\hline Underweight $($ WA $)(\mathrm{n}=42)$ & & \\
\hline$<-3$ SD & Severely underweight & $1(2.3)$ \\
$\geq-3<-2$ SD & Underweight & $1(2.3)$ \\
$\geq-2<+2$ SD & Normal & $24(56)$
\end{tabular}

\begin{tabular}{llc}
\hline Wasted $($ WH/BMIA) $(\mathrm{n}=42)$ & & \\
\hline$<-3$ SD & Severely wasted & $0(0)$ \\
$\geq-3<-2$ SD & Wasted & $1(5)$ \\
$\geq-2<+2 S D$ & Normal & $41(95)$ \\
$>+1 S D$ & Risk of overweight & $13(30.2)$ \\
$\geq+2<+3$ SD & Overweight & $2(4.7)$ \\
$\geq+3$ SD & Obesity & $1(2.3)$
\end{tabular}

Stunted (HAZ) $(\mathrm{n}=42)$

\begin{tabular}{llr}
\hline$<-3$ SD & Severely stunted & $6(14.3)$ \\
$\geq-3<-2$ SD & Stunted & $14(33.3)$ \\
$\geq-2<+2 S D$ & Normal & $22(52.4)$
\end{tabular}

WA- weight-for-age

HAZ- height-for-age

SD- standard deviation
WH- weight-for-height

BMIA- body mass index-for-age 


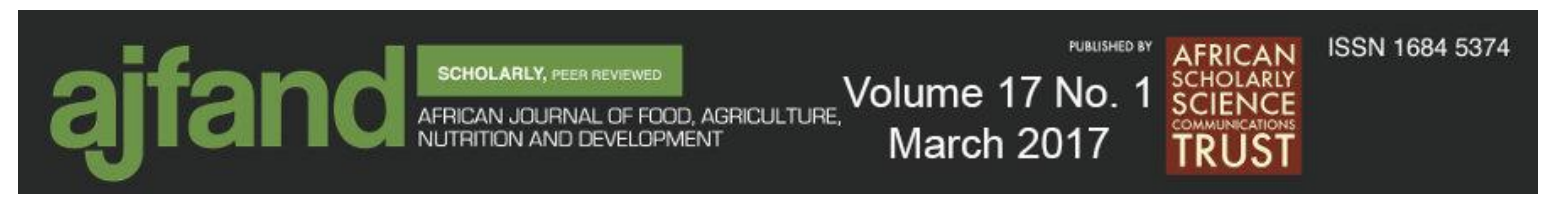

Table 5: Haematological and biochemical results

\begin{tabular}{lll}
\hline Variables & Mean \pm SD & $\begin{array}{c}\text { Normal range (Burtis } \\
\text { et al. 2008) }\end{array}$ \\
\hline Red blood count & $4.7 \pm 0.5$ & $4.0-5.4 \mathrm{X} 106 / \mathrm{mm} 3$ \\
Haemoglobin & $13.1 \pm 1.7$ & $12.0-14.0 \mathrm{~g} / \mathrm{dl}$ \\
Haematocrit & $40 \pm 43$ & $36.0-44.0 \%$ \\
Mean cell volume & $84.2 \pm 5.0$ & $77-91 \mathrm{fl}$ \\
White blood count & $5.4 \pm 1.3$ & $4.5-13.5 \mathrm{X} 103 / \mathrm{mm} 3$ \\
Total protein & $75.2 \pm 6.7$ & $64-83 \mathrm{~g} / \mathrm{l}$ \\
Albumin & $43.4 \pm 4.6$ & $37-52 \mathrm{~g} / \mathrm{l}$ \\
Iron & $15.2 \pm 5.1$ & $9-31 \mu \mathrm{mol} / 1$ \\
Ferritin & $31.2 \pm 16.9$ & $12-200 \mu \mathrm{g} / 1$ \\
Transferrin & $2.8 \pm 0.58$ & $2-4 \mathrm{~g} / 1$ \\
\hline
\end{tabular}

SD- Standard deviation 


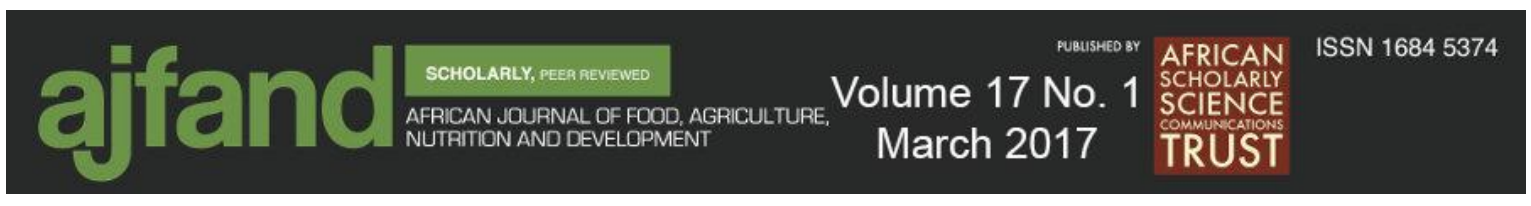

\section{REFERENCES}

1. World Hunger Facts (WHF). World hunger education services. 2009. Available from:

http://www.worldhunger.org/articles/learn/world\%20hunger\%20facts\%20.html.

Accessed 07/08/2011.

2. International Food Policy Research Institute. Global nutrition report: from promise to impact ending malnutrition by 2030. Washington, DC. 2016.

3. UNICEF. World Food Day: Protecting children from malnutrition, 2006. Available from http://www.unicef.org/nutrition/index_36170.html. Accessed 15/09/2011.

4. Van de Poel E, Hosseinpoor AR, Speybroeck N, Van Ourti T and J Vega Socioeconomic inequality in malnutrition in developing countries. Bulleting of the World Health Organization. 2008; 86: 241-320.

5. Walker SP, Wachs TD, Gardner JM, Lozoff B, Wasserman GA, Pollitt E, Carter JA and International Child Development Steering Group. Child development: risk factors for adverse outcomes in developing countries. 2007; 369: 145-57.

6. Hui Liu Y and MT Stein Feeding behaviour of infants and young children and its impact on child psychosocial and emotional development. Encyclopedia on Early Childhood Development. Second Edition. University of California San Diego. United States of America. 2013.

7. Bourne LT, Hendricks MK, Marais D and B Eley Addressing malnutrition in young children in South Africa. Setting the national context for paediatric food-based dietary guidelines. Matern. Child Nutr. 2007; 3(4): 230-238.

8. Boshoff E and MS Kgaphola Availability, access and utilization of food in rural communities: a conceptual framework in fundamentals of nutrition security in rural development. In: Fundamentals of nutrition security in rural development. Schonfeldt H (Ed.). 2006; 3:312-323.

9. Saloojee H, Maayer TD, Garene ML and K Kahn What's new? Investigating risk factors for severe childhood malnutrition in a high HIV prevalence South African setting. Scand. J. Public Health. 2007; 69:96-106.

10. Human Sciences Research Council and Medical Research Centre. The South African National Health and Nutrition Examination Survey. SANHNES-1. Cape Town, Human Sciences Research Council (HSRC Press), 2013. 


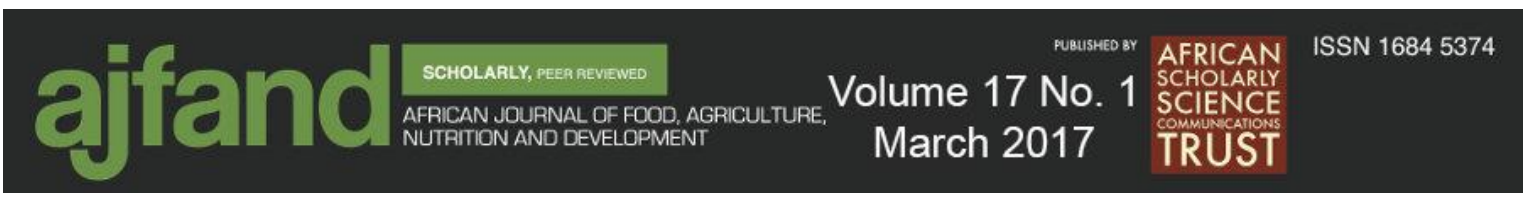

11. Pridmore $\mathbf{P}$ Impact of health on education access and achievement: a cross-national review of the research evidence. Institute of Education. University of London. 2007.

12. The survey system. Sample size calculator. http://www.surveysystem.com/sscalc.htm. 2012. Accessed: 10/10/2012.

13. De Wet T, Patel L, Korth $\mathbf{M}$ and $\mathbf{C}$ Forrester Johannesburg poverty and livelihoods study. Centre for Social Development in Africa. Johannesburg. University of Johannesburg. 2008.

14. Maclntyre U Dietary intakes of Africans in transition in the North West Province Potchefstroom: PU for CHO. Dissertation - PhD. 1998; 450.

15. Quintó L, Aponte JJ, Sacarial J, Espasa M, Aide P, Mandomando I, Guinovart C, Macete E, Navia MM, Thompson R, Menéndez $\mathrm{C}$ and PL Alonso Haematological and biochemical indices in young African children: in search of reference intervals. Trop. Med. Int. Health. 2006; 11(11): 1741-1748.

16. Langenhoven ML, Kruger M, Gouws E and M Faber MRC Food Composition Tables. 3 ed. Parow: South African Medical Research Council, 1991.

17. Institute of Medicine. Dietary reference intakes: Applications in dietary assessment. Food and Nutrition Board. Washington DC. National Academy Press, 2000.

18. World Health Organisation (WHO). Growth reference standards. 2007.

Available from: http://www.who.int/growthref/who2007/en/index.html. Accessed: $10 / 11 / 2011$.

19. Statistics South Africa (SSA). General household survey. 2014. Pretoria. South Africa.

20. Affordable Land and Housing Data Centre (ALHDC). Orange Farm. Available from: http://www.alhdc.org.za/static_content/?p=1342. Accessed 29/02/2016.

21. Kirsten AP and D Marais The influence of socio-demographic factors on the nutritional status of children in the Stellenbosch area, Western Cape. S. Afr. J. Clin. Nutr. 2013; 26(3):124-131.

22. Schoeman S, Fiber M, Adams V, Smuts C, For-Ngomane N, Laubscher J and M Dhansay Adverse social, nutrition and health conditions in rural districts of the KwaZulu-Natal and Eastern Cape Province. S. Afr. J. Clin. Nutr. 2010; 23:140-147.

23. Statistics South Africa (SSA). Statistics release: Mid-year population estimates, 2010. http://www.statssa.gov.za. Accessed 16/03/2013. 


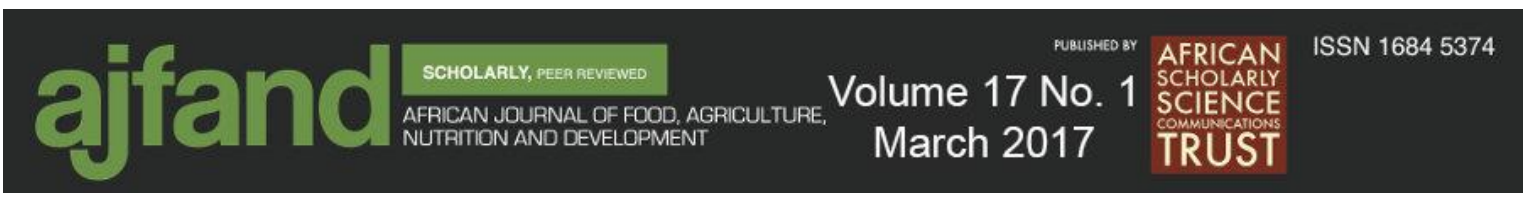

24. Peltzer K, Davids $\mathbf{P}$ and $\mathbf{P}$ Njuho Alcohol use and problem drinking in South Africa: Findings from a national population-based survey. Afr. J. Psychiatry. 2011; 14:30-37.

25. Selepe BM, Mtyingizane SS and FM Masuku Factors contributing to household food insecurity in Mhlontlo area, Eastern Cape, South Africa. J. Hosp. Manage. Tourism. 2015; 4(1): 2223-814X.

26. Bradshaw D, Pillay-Van Wyk V, Laubscher R, Nojilana B, Groenewald P, Nannan N, and C Metcalf Causes of death statistics for South Africa: challenges and possibilities for improvement. Tygerberg. Burden of Disease Research Unit. MRC 2010.

27. Grobbelaar HH, Napier CE and W Oldwwage-Theron Nutritional status and food intake data on children and adolescents in residential care facilities in Durban. $S$. Afr. J. Clin.Nutr. 2013; 26 (1): 29-36.

28. Jang SY Association of food insecurity, socioenomic status and type 2 diabetes among Mexican-Americans and Non-Hispanic whites in the United States. Graduate School-New BRUNSWICK, Rutgers. The State University of New Jersey. 2009.

29. Webster-Gandy J, Madden A and M Holdworth Oxford handbook of nutrition and dietetics. A practical and accessible guide to nutrition and dietetics. Oxford University Press. New York. 2006.

30. Papathakis PC and KE Pearson Food fortification improves the intake of all fortified nutrients, but fails to meet the estimated dietary requirements for vitamin A and B6, riboflavin and zinc in lactating South African women. Public Health Nutr.2012; 15(10):1810-1817.

31. Higgs NT Measuring and understanding the wellbeing of South Africans: Everyday quality of life in South Africa. Soc. Indic. Res. J. 2007; 81(2):331-356.

32. Human Sciences Research Council (HSRC). Nutritional status of children-media release No. 2. Cape Town. South Africa. 2013.

33. Faber $\mathbf{M}$ Nutrition in vulnerable communities in economically marginalized societies. J. Livestock. Sci. 2010; 130: 110-114.

34. Meme MM, Kogi-Makau W, Muroki NM and RK Mwadime Energy and protein intake and nutritional status of primary school children 5 to 10 years of age in schools with and without feeding programme in Nyamembe district, Kenya. United Nations University. 2008. 


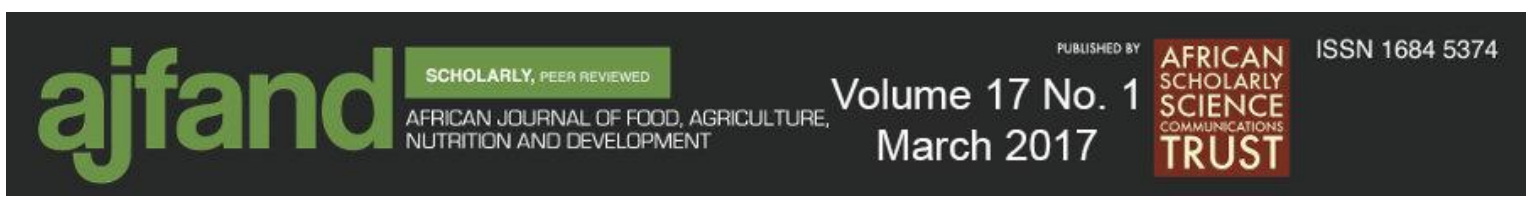

35. Food and Agriculture Organisation (FAO). The state of food insecurity in the world: Meeting the 2015 international hunger targets: taking stock of uneven progress. United Nations, Rome. 2015.

36. Oldewage-Theron WH and AA Egal Nutritional knowledge and nutritional status of primary school children in QwaQwa. S. Afr. J. Clin. Nutr. 2010; 23(2):149-154.

37. Babar NF, Muzaffar R, Muhammad AK and S Imdad Impact of socioeconomic factors on nutritional status in primary school children. J. Ayub. Med. Coll. Abbottabad. 2010: 22(4).

38. National Institute of Health (NIH). Maintaining a healthy weight on the go. A pocket guide. U.S Department of Health and Human Services. National Heart Lung and Blood Institute. No. 10-7415. 2010.

39. Torun B Short- and long-term effects of low or restricted energy intakes on the activity of infants and children. Institute of Nutrition of Central America and Panama (INCAP). Guatemala City. Guatemala. 1989.

40. Shetty PS Adaptation to low energy intakes: the responses and limits to low intakes in infants, children and adults, Eur J Clin Nutr. 1999: S14-33.

41. Berry $\mathbf{L}$ and $\mathbf{M}$ Hendricks Statistics on Children in South Africa: NutritionWasting in children. 2010. Available from http:// www.childrencount.ci.org.za. Accessed 11/10/2012.

42. Department of Health. Combating malnutrition in South Africa. Input paper for health road map. 2008.

43. Matthew AK, Amodu AD, Sani I and D Solomon Infant feeding practices and nutritional status of children in North Western Nigeria. Asia. J. Clin. Nutr. 2009; 1(1):12-22.

44. Sharkey JR, Dean WR and CM Johnson Association of household and community characteristics with adult and child food insecurity among Mexican-Origin households in Colonias along the Texas-Mexico border. Int. J. Equity Health. 2011; 10(9).

45. Shariff ZM, Bukhari SS, Othman S, Hashim N, Ismail M, Jamil Z, Kasim SM, Paim L, Samar BA and ZAM Hussein Nutrition education intervention improves nutrition knowledge, attitude and practices of Primary School Children: A pilot study. Int. Electron. J. Health. Edu. 2008; 11:119-132.

46. Pereira LM The Future of South Africa's Food System: What is research telling us? SA Food Lab. South Africa. 